INTRAPERITONEAL RUPTURE OF THE BLADDER IN A GIRL, AGED FIVE YEARS,

WITH SEPARATION OF THE RIGHT OS PUBIS AT ITS EPIPHYSEAL LINES; ABDOMINAL SECTION; SUTURING OF THE BLADDER ; REOOVERY.

BY H. BETHAM ROBINSON, M.S. LOND., F.R.C.S. ENG. ASSISTANT STRGEON TO, AND SURGEON IN CHARGE OF THE THROA DEPARTYIENT, FTC, AT, ST, THOMAS'S HOSPITAL; SURGEON TO THE EAST LONDON HOSPITAL FOR CHILDREN, SHADWELL.

IN September, 1901, an interesting summary of all the recorded cases of traumatic rupture of the bladder appeared by Alexander in the Annals of Surgery and previously to this statistical papers dealing with the same subject had been published by Kerr, in the Annals of Surgery, vol. xvii., 1893, and by Miles, in the Transactions of the Royal Medical and Chirurgical Society, vol. xxvii., 1895. From a perusal of these papers it will be of interest that the following case is the youngest that has been operated on (according to available records) up to date ; there have been two cases of children seven years of age and one of nine years of age.

Traumatic rupture of the bladder, whether extraperitoneal or intraperitoneal, may exist alone or very frequently is attended by damage to the pelvic girdle; if the rent is extraperitoneal the broken pelvis has probably played a part in causing the wound, whereas in the intraperitoneal form it may be only an accidental associate due to the same crushing force: an accepted explanation in the latter is that it may be the crowding back of a full bladder on the sharp lumbo-sacral angle. In this particular case the bladder had been distended and from the tender years of the child was abdominal in position. Although the bladder wound in thi case had an accompanying damage to the pelvis the latter did not cause it; the wheel passed obliquely over the abdomen from left to right, causing the bladder rent to be also oblique and lower on the same side as the fractured pelvis.

On March 11th, 1903, the child was playing in the road when she was knocked down by a cart, the wheel passing over her abdomen. This occurred at 2 P.M. and at 4.30 she was brought to the hospital and admitted. She was pale, restless, and very collapsed, with a feeble pulse of 128 and respirations 28, with grunting expiraticn. Her temperature was $97^{\circ} \mathrm{F}$. Breathing was almost entirely thoracic in character bnt the upper part of the abdomen moved fairly; the lower part was rigid, moved very little on respiration, and was tender even to gentle palpation. On light percussion in the flanks there was evidence of the presence of a small quantity of intraperitoneal fluid and the whole abdomen appeared to be considerably distended. The child complained of pain and kept calling out that she wanted to pass urine but on trial she was quite unable to do so. The catheter withdrew about a couple of teaspoonfuls of nearly pure blood with a urinous odour. On manipulation of the pelvis soft crepitus could be obtained which was due to diastasis of the right os pubis at its epiphyseal lines. At 9.30 P. M., the immediate shock having passed off, the abdo men was opened by a three-inch incision in the mid-line and there was not found any blood extravasation in the cellular tissue. On incising the peritoneum a collapsed bladder was found which was brought up into the wound On the superior surface was a rather oblique rent running from one obliterated hypogastric artery to the other side through which the mucous membrance prolapsed and out of which a few drops of bloody urine could be squeezed; on the left side the rent came right up to the lateral reflexion of the peritoneum. The flanks contained some free urine which was mopped out with sponges and the peritoneum was then cleansed with sponges dipped in normal saline solution The rent in the bladder was carefully sutured with fine silk the interrupted stitches were inserted after Lembert's method and avoided the mucous membrane. Beyond the single row two or three extra stitches were put in where there seemed a weak spot. The abdominal incision was then closed except in its central part through which a gauze drain wrapped in green protective was passed down to the wound in the bladder. A soft catheter was placed in the bladder viâa the urethra. The child had some additional shock after the operation but speedily rallied when in bed. Her legs were kept tied together and no other fixation was used for the pelvis. On the 12th the drain was changed and there was a considerable amount of fluid in the dressings with a urinous odour. On the 15 th the wound had been dressed daily and there was now no suspicion of any urine on the dressings. The drain was removed and a small gauze drain was put in the gap in the abdominal incision. The child's condition was first class and there was free passage of urine through the catheter which was still retained. On the 18th the drain was removed altogether and on the 19th the catheter was taken out. For some days there was some incontinence of urine which gradually passed off. On April 4 th the child developed some bronchn pneumonia which all cleared up at the end of a week. She remained in hospital until May $4^{\circ} \mathrm{h}$ and was discharged walking quite well, without any difference in the length of the limbs and with perfect control of the bladder.

The history of the accident in this case and the early symptoms pointed plainly to the probable diagnosis which the passage of the catbeter confirmed. Such tests as inflation with air or injecting fluid into the bladder were not utilised for, in the first place, they were unnecessary to establish the diagnosis and, in the second place, such procedures are likely to do much more harm than good by causing greater diffusion of the escaped bladder contents over the peritoneum. Such a procedure can only be of academic interest and, as Alexander says, having the idea that the bladder is ruptured, at once operate and if on exposing the front of the bladder no damage is found then open the peritoneum and search for the rent. There is nothing particular to comment on the operation. No special stitching of the mucous membrane was done; a single layer of fine silk Lembert interrupted sutures, fortified by a few more beyond, was used for the sero-muscular coat. There was no peritonitis but the case was fortunately operated on early. After cleansing the peritoneal surface I thought it safer to use a small gauze drain for a short time; it can do no harm and it may be of great service should the stitching unfortunately not hold.

The last point is one that has always been debateablenamely, the after-treatment of the sutured bladder. Excluding from the question putting a tube into the bladder suprapubically, it is a moot point whether there should be drainage per urethram or regular catherisation. Alexander has shown that of 39 cases there was an infinitesimal advantage gained by continued drainage ; one thing is quite certain, both from the patient's and surgeon's standpoint, the drainage is much simpler.

Upper Wimpole-street, $\mathrm{W}$.

\section{A CASE OF ACUTE SULPHONAL POISONING.}

By ALFRED E. HIND, F.R.C.S. ENG.

THE patient, a single woman, aged 27 years, had been under treatment suffering from melancholia. She had previously been five years in an asylum. She was now living with her parents while arrangements were being made for sending her to another asylum. I was called at $9 \mathrm{~A}$. M. on Dec. 17th, 1903, by her father who stated that he was unable to wake his daughter and that he suspected that she had taken three bottles of sulphonal, each containing 25 tablets, five grains in each, with the exception of two tablets found in the bedroom. In all she had taken 365 grains. On arrival I found the patient comatose and unable to be roused. There was no cyanosis. She was slightly pale. The pulse was 30 and feeble, the respirations were 15 , and the temperature was $98^{\circ} \mathrm{F}$. The corneal reflex, the kneejerks, and the radial reflex were absent. The pupils had medium contraction and reacted sluggishly. She had spoken rationally a few words early that morning. The bowels had opened on the previous day. The patient had been in the habit of taking sulphonal for insomnia and had threa ened suicide. The stomach was washed out with about a gallon of warm water wbich returned quite clear. A large enema of soap and water was given and retained. The urine was drawn off by catheter; it was clear and abundant. Half a pint of hot coffee was passed by a tube 
into the stomach and one-thirtieth of a grain of strychnine and one-fiftieth of a grain of digitalin were injected bypodermically. The patient was visited again in the evening; her condition was unchanged except that the corneal reflex had returned. The catheter drew off about three pints of clear urine. The bowels had not acted. On the 18th she was again visited. She had roused sufficiently in the night to swallow some coffee. Three pints of urine were drawn off by catheter and a pint of hot milk with two minims of croton oil was passed by a tuke into the stomach. The bowels had not opened. The patient was surrounded by hot-water bottles. In the evening the bowels had not opened and her condition was unchanged. The pulse was 100 , the respirations were 15 , and the temperature was $98^{\circ}$. Hot milk and three minims of croton oil were given by a tube which was almost immediately followed by vomiting. Some of the gastric contents being inhaled necessitated energetic treatment to restore breathing and to relieve cyanosis, under which treatment the patient roused considerably but soon relapsed into lethargy. An enema of soap with five minims of croton oil resulted in a small evacuation, chiefly enema, but some fæcal matter was present. Again three pints of urine were drawn off and a hypodermic injection of digitalin and strychnine was given as before. The patient was visited at $9 \mathrm{P} \mathrm{M}$.; half a pint of urine was drawn off. Her condition was unchanged. On the 19 th at $10 \mathrm{~A}$ M. she was cyanosed. The respirations were 30 , the pulse was 112 , and the temperature was $1035^{\circ}$. No physical signs of pneumonia were detected but her condition was probably affected by the inhalation of the gastric contents on the previous day. She was rather more collapsed and still unconscious. She had had a nutrient enema of egg and milk which she had retained. Hypodermic injection was given as before. At 1 P.M. the respirations were 40 , the pulse was 130 , and the temperature was $103^{\circ}$. One pint of urine was drawn off One-thirtieth of a grain of strychnine was given hypo dermically. At 630 P M. the respirations were 44, the pulse was 130 , and the temperature was $103.8^{\circ}$. Three quarters of a pint of urine were drawn off. One-thirtieth of a grain of strychnine and ore-sixtieth of a grain of digitalin were again given. The patient showed a slight return of consciousness. She had retained the nutrient enema of milk and egg and had spoken a few inarticulate words during the day. After the hypodermic injection the respirations fell to 30 , the pvise to 112 , and the patient had a better appearance. On the 20 th the respirations were 32 , the pulse was 112 , and the temperature was $103 \cdot 8^{\circ}$. One pint of urine was drawn off. The cardiac action was much stronger. The radial reflex and the knee-jerks had returned. The patient now appeared to notice ber surroundings. The bowels had opened slightly. The nutrient enemata were retained. A cert. in sweet chloroform.like odour had been noticed in the bre-ths since the first visit and lately also in the urine. The blddder remained in an atonic state and air entered after the urine was expelled by pressure on the abdomen. At 6.30 P.M. the pulse was 90 , the respirations were 20 , and the temperature was $100^{\circ}$. She was slightly restless and had been trying to get out of bed. She had passed urine under her and the bowels had opened slightly. She had spoken incoherently during the day at intervals. On the 21 st she had a restless night and was more conscious. The pulse was 80 , the respirations were 20 , and the temperature was $99^{\circ}$. The catheter drew off one and a half pints of urine. The bowels had opened slightly. She retained the nutrient enemata and had taken fluids by the mouth. At 6 P M. the pulse was 80 , the respirations were 25 , and the temperature was $994^{\circ}$. She was steadily regaining consciousness. Her speech was staccato and cerebration was slow. The catheter drew off three quarters of a pint of urine. On the 22 nd the pulse was 80 , the temperature was $98 \cdot 4^{\circ}$, and the respirations were 15 . She had been upon the stool but the bowels had not opened. She still took food by the mouth and had passed urine normally. She volunteered the information that she swallowed the above amount of sulpbonal at 11 o'clock on the evening of the 16th with suicidal intent. On the 23rd the pulse was 80 . the respirations were 15 , and the tem. perature was $994^{3}$. The bowels had opened. The catheter drew off three-quarters of a pint of urine; she was menstruating. She was much quieter and taking food fairly by the mouth. Four drachms of sulphate of magnesium were given in the morning and repeated in the evening. On the 24 th she was still improving. The bowels had opeced twice.
She passed urine on the stool; the catheter drew off four ounces oniy. She was taking food better. The pulse was 80 and the temperature was $984^{\circ}$. She slept well. Speech and cerebration were very little altered. On the 25 th she had markedly improved. Her speech was clear and cerebration was most active. The bowels were well opened; urine was passed naturally. She was taking food much better and she slept well. From this day her convalescence was uninterrupted as regards the sulphonal poisoning and on Jan. 2nd she was sent to an asylum.

As regards the treatment of the case, with no definite data to go on, and a strong presumption of her having taken sulphonal, washing out the stomach seemed to be the right step, although, as it subsequently turned out, it was perhaps of little use as some 12 hours had already elapsed. Althongh the large enemata were retajned they doubtless helped to eliminate a large amount of the poison by the kidney, and as for medicine, strychnine and digitalin seemed to be the only drugs indicated. The inhalation of the stomach contents was an unfortunate incident which, however, did not seem to affect the case very seriously, although septic pueumonia at one time threatened to complicate a most intractable case. Coma, absence of the reflexes mentioned above, including atony of the bladder and the bowel, were the most striking features in the case. The accidental inhalation was no doubt due to this condition also. The heart sounds were very feeble, more so than the pulse would suggest. Her condition at the first visit gave very little clue to the cause and it was only on the strong presumption of what had happened that sulphonal poisoning was diagnosed, Her recovery, however, was complete and happened more or less abruptly on the eighth day. No anorexia or constipation remained. Her mental condition also remained unaffected. Althongh when first seen "her condition appeared to be critical, if not even hopeless, in the light of her subsequent recovery one is apt to regard the danger incurred with less fear. Other cases reported appear to have been followed by protracted evil effects and to have recovered very slowly. Examination of the urine showed a slight trace of albumin, no sugar, 4.5 per cent. of urea, and no blood. It was clear, light-coloured, and of specific gravity 1030 ; it had no smoky tint. The absence of a spectroscope precluded the test for hæmatoporphyrin. I should be glad to have suggestions as to any antidole for sulphonal if such exist.

Jersey.

\section{A CASE OF ACUTE TRAUMATIC CHOLECYSTITIS.}

By FRED. J. SMITH, M.D. OxON., F.R.C.P. LoND., PHYSICIAN TO THE LONDON HOSPITAL;

AND

C. W. MANSELL MOULLIN, F.R.C.S. ENG., SENTOR SURGEON TO THE LONDON HOSPITAX.

A MAN, aged 59 years, was walking to business on Dec. 29th, 1903, when he slipped on some ice and fell. The history of how he fell is not quite clear, though be himself asserted that it was "all his length on his right side." $\mathrm{He}$ complained at the time of some pain but went to business and seemed no worse for the accident until Jan. 3rd, 1904, when he complained to his wife that his side hurt him, but he did not take much notice of it. On the 5th his bowels acted as usual in the morning and again at about 2 and 4 o'clock in the afternoon. (The sequel suggests that these actions were melænic.) Soon after the second action he was sick and in a little while was seized with a severe fain in the abdomen. He was shortly afterwards seen by Dr. Mowbray Henderson who administered morphia. The pain continued all that night sufficiently severely to keep him awake. He vomited on the morning of the 6th and again on the following morning but not subsequently. His bowels never acted after the loose motions on the 5th notwithstanding the administration of two enemata on the 6 th and two on the 7 th; the second enema on the latter date brought away a little fæcal matter. On the 8th the abdomen began to swell and Dr. Henderson asked me (F. J. S.) to see him at 1 P.M. as a case of intestinal obstruction. I found the patient lying in bed quite quiet and sensible; his face was very congested, almost blue, like the face of bad "bronchitis with emphysema." The pulse was 